\title{
Motivation to Use Free Floating Car Rental Service in Riga: The CARGURU Case
}

\author{
Karlis Kreslins ${ }^{1}$, Ion Cararus ${ }^{2}$, Marius Onofrei ${ }^{3}$ and Tatjana Vasiljeva ${ }^{4}$ \\ ${ }^{1}$ Ventspils University of Applied Sciences, Ventspils, Latvia \\ ${ }^{2}$ Orange Systems, Chisinau, Republic of Moldova \\ ${ }^{3}$ University of Luxembourg, Luxembourg \\ ${ }^{4}$ RISEBA University, Riga, Latvia
}

Coresspondence should be addressed to: Karlis Kreslins, karlis.kreslins@venta.Iv

Received date:17 February 2021; Accepted date: 9 August 2021; Published date: 14 December 2021

Academic Editor: Jelena Franjković

Copyright (C) 2021. Karlis Kreslins, Ion Cararus, Marius Onofrei and Tatjana Vasiljeva. Distributed under Creative Commons Attribution 4.0 International CC-BY 4.0

\begin{abstract}
Digital transformation and digitalization in general have made a significant impact on the service industry, including banking, commerce and renting. Technology, including mobile applications, has converted traditional and formerly inseparable services into ones that can be used from any place and at any time. The paper explores customer motivating factors for using free-floating car rental service (FFCRS) in Riga with particular emphasis on utilitarian and hedonic motivators. A single case study design is used as the basis for the research methodology, which includes qualitative and quantitative data collected from other case studies, theoretical papers, in-depth interviews with company management and surveys of customers and non-users. Analysis of the findings demonstrates four highly significant motivators which are trust, driving disincentives, environmental consciousness and burden of ownership, and which directly determine the frequency of CARGURU service usage.
\end{abstract}

Keywords: Free-floating Car Rental Service, Entrepreneurship, Customer Motivation

Cite this Article as: Karlis Kreslins, Ion Cararus, Marius Onofrei and Tatjana Vasiljeva (2021), "Motivation to Use Free Floating Car Rental Service in Riga: The CARGURU Case", Journal of Marketing Research and Case Studies, Vol. 2021 (2021), Article ID 127627, DOI: 10.5171/2021.127627 


\section{Introduction}

Over the last few decades, modern technologies and digital solutions have changed the economy and the service industry. According to Berry (2006), technology has converted traditional services into new online services which can be accessible at any time all over the globe. Several years ago, in order to rent a car, one had to visit a rental company physically and pay a deposit, but nowadays the entire rental process requires just a few clicks in the relevant application.

Digitalization also entails the customers' side and people have integrated modern technologies into their communication, work and studies. Moreover, as mentioned by SecurEnvoy (2012), two out of three people suffer from nomophobia - "the fear of being out of mobile phone contact". This has led to alternative ways of consumption, and as indicated by Bardhi and Eckhardt (2012), one such alternative mode is access-based consumption (ABC), which ensures marketmediated transactions where no transfer of ownership occurs.

Free-floating car rental service (FFCRS), which serves as an example of the ABC pattern, is a relatively new service. The first FFCRS provider in Latvia is the company CARGURU, established in Riga. The service offers an easy way to rent a car by enabling customers to find available vehicles via a mobile application and drop them off in designated areas after using them. According to Becker (2015), such a service is convenient for urban areas, as it increases efficiency and controls traffic congestion. FFCRS also decreases pollution and the costs are lower compared to personal car ownership rates. Ryden and Morin (2005) estimate that the use of FFCRS helps to reduce carbon dioxide emissions by $39 \%$ per user.

Shaheen, Sperling and Wagner (1998) were among the first researchers who analyzed the social benefits of FFCRS, and they discovered that environmental consciousness, accessibility and driving disincentives are the main motivators for customers to use this service. The motivation of FFCRS customers has not been researched before in Latvia; therefore, this study will analyze factors which motivate customers to use this service in Riga.

\section{Theoretical Framework}

Free-floating car rental services evolved at the beginning of the $21^{\text {st }}$ century as an addition to the traditional station-based car rental services. As noted by Becker (2015), userfriendly mobile applications linked to the service permitted users to find a car in their proximity. Digital mapping unlocked the FFCRS potential and enabled service providers to track the cars. Successful examples of the FFCRS business include the Swiss FFCRS provider Catch a car, the London-based free-floating car rental operator DriveNow, and Car2Go, which operates in Germany as well as in some other countries in Europe and beyond.

CARGURU was established in Riga in May 2017, and the business model was inspired by and adopted from FFCR services in the USA. Anyone older than 21 with at least two years' driving experience is eligible to register in the CARGURU system by downloading the mobile application. A potential user of CARGURU needs to enter certain personal information and, after validation, gets access to the services within one business day. After that, the client can find the closest available car on the map using the mobile application. Moreover, users of CARGURU, especially frequent clients, receive different offers and bonuses. All CARGURU cars are identically painted with the company logo, which helps to attract potential customers. Regarding competitors, CityBee and Fiqsy, which consequently entered the FFCR services market in Latvia in 2019 and 2020, may be regarded as direct competitors. Two major ridesharing taxi providers, Bolt and Yandex taxi, may be considered as indirect 
competitors of CARGURU and the services the company provides.

One of the crucial factors behind the success of a business in the long term is determination of customers' needs and expectations. According to Camilleri (2017), it is important to identify what motivates customers to buy or use a product or service. Kay (2003) noted that customer motivation has been studied for various industries including retail, tourism, and medicine. Motivation can be characterized as the desire of a customer to meet his/her needs. Moreover, Solomon, Bamossy and Askegaard (2007) determined that the need behind the motivation may be either utilitarian or hedonic.

Concerning the utilitarian side, some of the latest studies, i.e. described by Tussyadiah (2015), have revealed that when buying, people make irrational financial decisions, and they do this being motivated by other factors that require experiential input. Hedonic need involves emotional response, and Childers (2001) noted that customers with hedonic motivations can be characterized by their sense of entertainment which interacts with the service or product. Therefore, hedonic motivations play an important role in consumer decision-making. Nevertheless, several decades ago Holbrook and Hirschmann (1982) revealed that both utilitarian and hedonic motivations may be significant in the decision-making process. Both groups of motivation factors have also been analyzed in relation to usage of freefloating car rental services.

Studying the usage patterns of an FFCR service in Switzerland, Becker (2015) discovered that the socio-demographic profile of FFCR service users can be characterized as male, employed, and under 36 years old, with a medium to high income level and a higher education degree. Based on the results from other surveys carried out in Paris, London, Madrid and other cities, this sociodemographic pattern to a certain extent can be generalized.
In terms of utilitarian factors, Bardhi and Eckhradt (2012) consider that utility and economic affordability are the principal determinants of FFCR service usage. Möhlman (2015), who studied the topic of FFCR services, also concluded that the utility factor can be defined as the perception of customers regarding the price compared to other means of transportation, i.e. taxis or station-based car rentals. Along with economic reasons, as noted by Bardhi and Eckhradt (2012), customers are motivated to use FFCR services for their convenience and/or flexibility. In the context of FFCR, the importance of convenience is revealed as consumers' desire to reach a destination in the most convenient way, which excludes the effort involved in planning ahead as well as the physical energy required to obtain a car using station-based car rental schemes. Research carried out by Arcidiacono and Pais (2018) also stressed that FFCR service availability, accessibility and customer incentives to use the service are important utilitarian factors to be considered.

Risks of ownership is another factor which should be considered, and this is supported by Le Vine and Polak (2007), who determined that the likelihood of reducing ownership is positively correlated with a higher usage of renting. FFCR services directly reduce risks and responsibilities related to ownership. Also, as stated by Shaheen (2009), FFCR service is preferred by customers who not only want to avoid the burden of ownership but also seek to fill the gap between transit and private cars. A PricewaterhouseCoopers' (2014) report on automotive leasing and car sharing indicated that traffic congestions and high parking costs are essential factors that drive the growth of free-floating car sharing services.

It has been shown by several researchers, including Kim (2006), that utilitarian motivation is significant in explaining customer behaviour and decision-making. However, other researchers have revealed that consumers are looking for entertainment and social interaction, which, as stated by Arnold and Reynolds (2003), are hedonic 
factors. Möhlamann (2015) also notes that user experience positively correlates with motivation to use the service repeatedly, which means that FFCR service clients may be motivated by curiosity and/or enjoying the experience while driving the car.

Social interaction as the channel of transmitting feedback and reviews is another important hedonic factor. Kim et al. (2011) found that nowadays consumers do not make any reservations for hotels, guest houses, or restaurants without prior checking of reviews available in online media. FFCR services can be assessed by trying them out; therefore, positive peer reviews can play a significant role in attracting customers to the services. Moreover, interviews with CARGURU users revealed that commentaries in Facebook and other social networks were crucial for them in making a decision to use the service.

Mutual trust between service providers and users also raises the motivation to use the service. Tussyadiah (2015) stresses that reputation is an essential hedonic factor, and participants of the online rental platform
Airbnb can serve as a successful example. Trust that the supplier provides good quality service is directly linked to the motivation of customers to exploit FFCR services.

Finally, customers increasingly care not only about their group of users but also about society and the environment. The number of environmentally conscious people who care about pollution and other destructive environmental practices has grown significantly during the last few decades, and this has made an obvious impact on consumer behaviour. Schlegelmilch et al. (1996) stressed that environmentally friendly service customers are willing to pay a premium price for cleaner and greener goods and services. FFCR is an environmentally friendly service as the cars are often equipped with energysaving or hybrid engines which minimise fuel consumption; therefore, one can expect a growing motivation to use it from the ecoconscious customer. Based on the literature review provided in the theoretical framework, Table 1 summarises the main utilitarian and hedonic factors.

Table 1. Summary of utilitarian and hedonic factors (created by the authors)

\begin{tabular}{|l|l|}
\hline \multicolumn{1}{|c|}{ Utilitarian factors } & \multicolumn{1}{c|}{ Hedonic factors } \\
\hline - economic affordability and price & - curiosity and new experience \\
- accessibility, availability and convenience & - social interaction and peer review \\
- customer incentives & - trust and reputation \\
- reduced burden of ownership & - environmental friendliness \\
\hline
\end{tabular}

\section{Research Methodology}

The research design is based on a single case study approach, which is relevant for studying customer motivation, including the rental industry, as stated by Gullstrand et al. (2015). A selection of case studies regarding FFCR companies from other countries where the services have been present for a longer period of time has also been used. Customer motivation was studied by using mixed methods of data analysis, i.e. qualitative and quantitative data.
The qualitative part of the research comprises discussion with the main players involved in FFCR services, i.e. CARGURU company representatives and customers. Several interview sessions were organized with the CEO of CARGURU and senior management. The purpose of the first interview session was to understand how the company addresses its customers, how the industry works and what the company representatives think their customers want or need. The next sessions were organized to discuss preliminary results, 
including opinions of customers regarding CARGURU and the main drivers for customers to use the FFCR service.

Besides the abovementioned discussions with company representatives, eight semistructured interviews were conducted with active users of CARGURU to reveal unexpected aspects of the customers. The interviews may indicate the response pattern of the participants based on their answers to open-ended questions. As suggested by Camilleri (2017), questions in a semistructured interview should not contain ambiguous wording, need to be easy to read and should have necessary explanations; therefore, a pilot questionnaire was designed and tested by ten CARGURU users.

The pilot testing revealed problematic items of the questionnaire as well as the difficulties respondents had when answering questions. Feedback from the discussion with customers in the initial phase also helped in modifying and changing questions which caused confusion. The final survey questionnaire consisted of nine sociodemographic questions and eight questions about motivational factors. The results collected from the survey were validated using a focus group interview with drivers who have never used CARGURU services.

Customer motivation was determined during the interview sessions, which had three implications for the research. First of all, initial intelligence about customer profiles and opinions about CARGURU were gathered. Secondly, an assessment of what motivates users to drive CARGURU cars was carried out. Thirdly, there was an analysis of what customers liked about the CARGURU service and how they perceive it in relation to alternatives. Finally, opinions of users on what they disliked about CARGURU and what they would like to be changed were determined.

To sum up, in order to gather initial insight into the business model, focus group discussions with the company management and active users were conducted followed by the generation and testing of the pilot questionnaire, obtaining results from the main customer survey and, ultimately, crosschecking the final results with non-users to receive insight on why they would or would not use the FFCR service of CARGURU.

\section{Main Findings and Discussion}

The interview with the CEO of CARGURU revealed that the concept of FFCR services was adopted in Latvia from the USA. During the interview, it was also confirmed that the target audience of CARGURU comprises users in the age group of 25 to 30 years old. The CEO of the company also indicated that the main reasons why clients use CARGURU services are cost savings, convenience and environmental consciousness. Moreover, it was also stressed by the senior management that emotional factors are essential, i.e. trust and gaining experience are among the most important hedonic factors.

Utilitarian and hedonic factors were discussed during the eight in-depth interviews with CARGURU users, who had different employment statuses, genders, income levels and educational backgrounds. Most of the respondents appreciated the prices as well as the ease of utilisation; thus, customers who value convenience are more motivated to use the FFCR service, which confirms the theoretical statement made by Shaheen et al. (1998). Nevertheless, driving disincentives proved to be a deterrent to using CARGURU services, i.e. several respondents were not satisfied with the limited official parking places where the car can be left after use.

During the in-depth interviews with CARGURU customers, it was found that positive overall experience and peer review are important motivators, i.e. some respondents mentioned that they like the freedom of driving themselves and that their friends or relatives shared positive feedback about the service. Mutual trust among the users and the company was mentioned as a 
significant factor in making the decision to use the service, and several respondents noted that the company delivers what it promises. Finally, the majority of the customers interviewed stressed their concerns about environmental changes; therefore, the use of
FFCR services offered by CARGURU may help to decrease pollution. Table 2 shows positive and negative factors noted by CARGURU users which foster the use of the service or may be barriers to attracting more frequent customers of the FFCR service.

Table 2. Summary of positive and negative factors mentioned by CARGURU users (created by the authors)

\begin{tabular}{|l|l|}
\hline \multicolumn{1}{|c|}{ Positive factors } & \multicolumn{1}{c|}{ Negative factors } \\
\hline - affordability (price) & - car availability when needed \\
- ease of use & - limited car fleet \\
- trustworthy service & - limited parking zones \\
- elimination of ownership burden & - IT-related issues, e.g. mobile telephone \\
- new driving experience & charging \\
- company relationship with customers & - GPS identification and Internet connection \\
& due to the weather conditions \\
\hline
\end{tabular}

Similar interviews were carried out with nonusers of CARGURU services, which helped the authors to ascertain positive factors regarding FFCR services from the viewpoint of potential customers and restricting factors which prevent potential users from using the company's services. Convenience for commuting, easy and fast registration, lack of ownership burden and environmental friendliness were mentioned as the most encouraging factors for using the service. Meanwhile, the main factors cited as preventing potential users from becoming CARGURU customers were monetary utility, including high rates and a complicated calculation procedure; convenience, which encompasses parking policy and parking zones; the need for an EU driving licence; the availability of cars; peer review and trust, i.e. a possible fine for damage; and lack of information about previous users. Table 3 summarises the opinions of FFCR service nonusers.

Table 3. Summary of positive and negative factors mentioned by non-users of CARGURU (created by the authors)

\begin{tabular}{|c|c|}
\hline Positive factors & Negative factors \\
\hline $\begin{array}{l}\text { - convenience for commuting } \\
\text { - fast and easy way to register and use the } \\
\text { service } \\
\text { - no costs related to car ownership } \\
\text { - environmentally friendly offer }\end{array}$ & $\begin{array}{l}\text { - necessity of a European driving licence } \\
\text { - too strict parking policy } \\
\text { - availability of cars when needed } \\
\text { - high rates and complicated calculation } \\
\text { process } \\
\text { - impossible to check technical condition of a } \\
\text { car } \\
\text { - possible fine for damage by the previous user } \\
\text { - lack of information about the previous users } \\
\text { - risk of getting in an accident } \\
\text { - limited advertisement about the company } \\
\text { online }\end{array}$ \\
\hline
\end{tabular}

Karlis Kreslins, Ion Cararus, Marius Onofrei and Tatjana Vasiljeva, Journal of Marketing Research and Case Studies, DOI: 10.5171/2021.127627 
Apart from the interviews mentioned above, a questionnaire was designed and distributed to CARGURU users via social networks. Overall, 204 responses were received from active FFCR service users which corroborated the socio-demographic profile of the customers. Regarding the frequency of use, more than a quarter of the customers surveyed were using the service often or daily, whereas the majority were occasional customers. In terms of age, $50 \%$ of the users were within the age range of 21 to 29 years old, while $14 \%$ and $36 \%$ respectively were within the age range of 30 to 35 years old and older than $35.72 \%$ of respondents hold a university degree, which might be reflected in the income level, i.e. $65 \%$ of respondents reported their income level as medium. Regarding gender, $2 / 3$ of users were men, which could be explained by the fact that in general male drivers in Latvia are more common than female drivers. The questionnaire results also showed that more than $2 / 3$ of customers live either in the centre of Riga or outside the centre in the Riga suburbs.

In terms of information channels, 39\% of respondents highlighted that social media were the primary source for obtaining information about CARGURU, followed by $33 \%$ of users, who received necessary information by word of mouth from friends or relatives. $28 \%$ of respondents became CARGURU users by spotting FFCR service cars throughout Riga city. Finally, in terms of purpose for usage, more than half of customers were renting CARGURU cars to get to work, whereas almost $35 \%$ were using cars for leisure driving, which includes shopping and leisure trips. Analysis of the results also revealed that regarding leisure driving, 37\% were not active FFCR service users compared to those $27 \%$ who use the cars for routine driving.

Based on the results from the interviews and customer survey, it can be concluded that burden of ownership is a strong motivator for active users, i.e. almost $50 \%$ of active users noted that costs related to owning a car are high. At the same time, customers who trust CARGURU become active users of the service, whereas concerns about the mutual trust between clients and FFCR hinder non-users from becoming clients. Regarding environmental consciousness, people who are initially eco-conscious choose CARGURU for this specific reason. As for driving disincentives for active users, time spent in traffic jams may be one issue, as this is closely related to the financial aspect, i.e. the mobile application counts the time when the car's engine is on and calculates respective costs. The risk of getting into an accident is a factor behind reluctance to use the service among non-users. Analysis of the results also clarified that the experience of trying out different new car models was not significant for CARGURU users, since at the time the research was carried out the company's car fleet was limited. Monetary utility was important for CARGURU clients, while non-users expressed their concerns about the complicated calculation procedures for the price for the ride. It was also noted by CARGURU clients that the service offers a convenient way to reach a destination in Riga; however, both current users and non-users also stressed the necessity to increase availability by expanding the car fleet. Finally, the results also showed that peer review plays a significant role in the adoption of the service, while later the price-quality ratio is more important for existing users.

\section{Conclusions and Recommendations}

Analysing customer motivators for a new product in the Latvian market, it can be concluded that environmental consciousness, trust, driving disincentives and burden of ownership are the main factors which motivate consumers to use FFCR services in Riga. Mutual trust between the users and risks/costs related to ownership are factors which drive the frequency of service usage; therefore, CARGURU should put more emphasis on these factors. 
Previous studies revealed that FFCR service users who perceive driving incentives as significant are more motivated to use the services. However, the case of CARGURU shows that people do not consider driving disincentives as a reason to switch to the services offered by CARGURU. This can be explained from the perspective of both users and non-users: traffic jams in Riga are common; thus, one may not only spend extra time but also very likely more financial resources for the ride.

Although previous research revealed that customers who perceive the service as environmentally friendly are more motivated to use it, this factor was not directly applicable to the case of CARGURU. This can be explained by the fact that users do not always act in an eco-conscious manner. Even if customers perceive the service as eco-friendly, they also understand that increased use of CARGURU cars entails polluting the atmosphere.

As for further research, a change in methodology should be introduced i.e. quantitative methods such as binary logistic regression model, since the results of the case study design might not be fully applicable to other FFCR services in Latvia. Another restricting factor is limitations in the population selected, since it comprises customers of a particular service in one type of region. Therefore, a larger population should be selected in further research so that the results can be applicable not only for customers in Latvia but also in other countries which use similar FFCR services.

Finally, selective memory bias may be present in the study, i.e. only $26 \%$ of the sample were active users, and the rest used the service occasionally. Therefore, some of the active users might not remember precisely the experience associated with the service. Consequently, the survey responses might not reflect the true hedonic values; thus, the experience-orientated factor might not be related to selective memory bias. It is likely that if the service is not frequently used, customers may either underestimate or overestimate the entertainment and enjoyment associated with the service, which means that the results of the user interviews may be biased. Therefore, as the CARGURU service is growing and new competitors are appearing in the Latvian market, further research should be conducted to obtain new insights into customer motivation.

\section{References}

- Arcidiacono, D. and Pais, I. (2018). Think mobility over: a survey of Car2go users in Milan. Multidisciplinary design of sharing services, ISBN 978-3-319-78098-6, 143161.

- Arnold, M.J. and Reynolds, K.E. (2003). Hedonic shopping motivations. Journal of Retailing, 79(2), 77-95.

- Bardhi, F. and Eckhardt, G. (2012). Access-based consumption: the case of car sharing. Journal of Consumer Research, 39(4), 881-898.

- Becker, H., Ciari, F. and Axhausen, K.W. (2015). Comparing car-sharing schemes in Switzerland: user groups and usage patterns. Transportation Research Part A: Policy and Practice, 97, 17-29.

- Berry, L.L., Shankar, V., Parish, J.T., Cadwallader, S. and Dotzel, T. (2006). Creating new markets through service innovation. MIT Sloan Management Review, 47(2), 56.

- Camilleri, M. (2017). Understanding customer needs and wants. Travel Marketing, Tourism Economics and the Airline Product, 29-50.

- Childers, T.L., Carr, C.L., Peck, J. and Carson, S. (2001). Hedonic and utilitarian motivations for online retail shopping behavior. Journal of Retailing, 77(4), 511535.

- Gulstrand Edbring, E., Lehner, M. and Mont, O. (2015). Exploring consumer attitudes to alternative models of consumption: Motivations and barriers. Journal of Cleaner Production, 123, 5-15.

- Holbrook, M.B. and Hirschmann, E. (1982). The experiential aspects of consumption: consumer fantasies, 
feelings, and fun. Journal of Consumer Research 9 (2), 132-140.

- Kay, P. (2003). Consumer motivation in a tourism context: Continuing the work of Maslow, Rokeach, Vroom, Deci, Haley and others. Proceedings of the 2003 Australian and New Zealand Marketing Academy Conference, ISBN 0868039837 9780868039831, 600-614.

- Kim, E.E.K., Mattila, A.S. and Baloglu, S. (2011). Effects of gender and expertise on consumers' motivation to read online hotel reviews. Cornell Hospitality Quarterly, 52(4), 399-406.

- Kim, H.S. (2006). Using hedonic and utilitarian shopping motivations to profile inner city consumers. Journal of Shopping Center Research, 13(1), 57-79.

- Le Vine, S. and Polak, J. (2017). The impact of free-floating carsharing on car ownership: Early-stage findings from London. Transport Policy. [Retrieved September 15, 2020], https://cpb-usw2.wpmucdn.com/hawksites.newpaltz.e du/dist/2/625/files/2017/10/FlexibleCS-Car-Ownp-Impacts-Postprint1ff0j5h.pdf

- Möhlmann, M. (2015). Collaborative consumption: determinants of satisfaction and the likelihood of using a sharing economy option again. Journal of Consumer Behaviour 14(3), 193-207.

- PricewaterhouseCoopers (2014). The shift from ownership to access: How will the automotive industry respond to new consumption models in China? [Retrieved September 15, 2020], https://www.pwc.de/de/publikationen/ assets/the-shift-from-ownership-toaccess.pdf
- Ryden, C. and Morin, E. (2005). Mobility services for urban sustainability: Environmental assessment. Report WP 6. [Retrieved September 15, 2020], https://cordis.europa.eu/project/id/EV K4-CT-2000-00042

- Schlegelmilch, B.B., Bohlen, G.M. and Diamantopoulos, A. (1996). The link between green purchasing decisions and measures of environmental consciousness. European Journal of Marketing, 30(5), 35-55.

- SecurEnvoy (2012). 66\% of the population suffer from Nomophobia the fear of being without their phone. [Retrieved September 15, 2020], https://www.securenvoy.com/en$\mathrm{gb} / \mathrm{blog} / 66$-population-suffernomophobia-fear-being-without-theirphone

- Shaheen, S., Sperling, D. and Wagner, C. (1998). Carsharing in Europe and North America: Past, present and future. Transportation Quarterly, 52(3), 35-52.

- Solomon, M., Bamossy, G. and Askegaard, S. (2007). Consumer behavior: A European perspective. Harlow: Financial Times/Prentice Hall, 90-100.

- Tussyadiah, I. (2015). An exploratory study on drivers and deterrents of collaborative consumption in travel. Information and Communication Technologies in Tourism. [Retrieved September 15, 2020], https://www.researchgate.net/publicati on/272023008_An_Exploratory_Study_o n_Drivers_and_Deterrents_of_Collaborati ve_Consumption_in_Travel. 